\title{
Study on 4PAM Radio over Fiber System Using Self-Mixing Technique
}

\author{
Luo Chen, Yufeng Shao*, Fuping Chen, Shilu Shen \\ College of Electronic and Information Engineering, Chongqing Three Gorges University, Chongqing, China \\ Email: "syufeng@163.com
}

Received 30 May 2016; accepted 20 August 2016; published 25 August 2016

\begin{abstract}
In this paper, a simplified optical millimeter-wave generated by two optical sidebands beating together in a $60 \mathrm{GHz}$ radio over fiber (RoF) system with $10 \mathrm{Gbit} / \mathrm{s}$ 4-pulse amplitude modulation (4 PAM) transmission signal is proposed and simulated. $10 \mathrm{Gbit} / \mathrm{s}$ electrical 4 PAM signals modulated are conveyed over the length of $40 \mathrm{~km}$ standard single mode fiber (SMF) and recovered via the self-mixing technique after detecting directly at the receiver. Graphs of time-domain wave, frequency-domain and optical spectrum are measured out in different period, and the comparison of error vector magnitude curves of NRZ and 4 PAM signals under the different length of fiber is accomplished. The capacity of 4 PAM modulation is higher, though NRZ performs better than 4 PAM selected in RoF system within $80 \mathrm{~km}$ of fiber length as shown in the simulation results.
\end{abstract}

\section{Keywords}

Optical Communication, 4PAM, RoF, Self-Mixing

\section{Introduction}

Recently, high-speed and large-capacity transmission has been the focus of attention in the field of communication as global data growing fast. Wireless, digital and broadband communication is the trend of communication industry development in the future. Various transmitting schemes including radio over fiber (RoF) attract strong interest of researchers as well as the large scale deployment of fiber to the building (FFTB), fiber to the office (FTTO), fiber to the home (FFTH) and fiber to the desk (FFTD) which are considered to be the potential solution of "the last mile" [1]. By the technology of RoF, radio frequency (RF) signal processing function centralized in the optical line terminal (OLT) is converted to mm (millimeter)-wave with lower attenuation through the photoelectric device, then distributed from a base station (BS) to a mobile station (MS) with antennas, the optical network unit (ONU) offers access points to various users [2]-[4]. As shown in Figure 1, the compact RoF optical access network is where high speed of text, voice, RF video data are provided to different service terminations between the OLT and ONU. RoF as an important method realizing the seamless integration of wired and wireless access system can offer high-throughput information with utilizing massive bandwidth of the fiber [5]. However, to reduce implementation costs is an essential issue for commercial applications. Orthogonal frequency

${ }^{*}$ Corresponding author. 


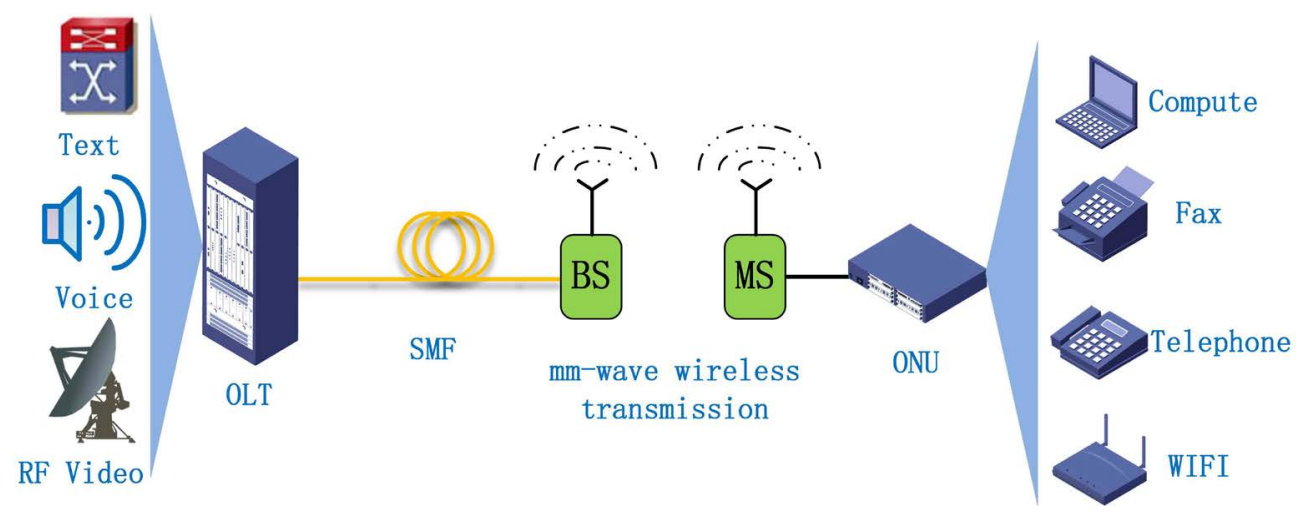

Figure 1. RoF system configuration (OLT: optical line terminal; SMF: single mode fiber; BS: base station; MB: mobile station; ONU: optical network unit).

division multiplexing (OFDM) is always used to modulate RF signals in RoF system [6] [7], meanwhile, the high peak-to-average power ratio (PAPR) is one of the main drawbacks of the OFDM modulation format, which not only degrees the performance of a linear amplified component but also pulls down overall property. In [8], a novel $60 \mathrm{GHz}$ RoF system was proposed and experimentally demonstrated with 16 QAM-OFDM downstream signals, which employed partial transmit sequence to diminish the high PAPR from the OFDM signals that will increase the computation complexity of the system. 4 PAM was implemented to release this condition we proposed in the work because of its straightforward process and low-cost structures [9].

In this paper, we propose a simulation scheme of 4 PAM-RoF optical access system with the Optiwave. The 4 PAM signal is intensive signal modulated by a Mach-Zehnder modulator (MZM) at baseband and directly detected by a positive-intrinsic-negative photodiode (PIN-PD), and two paths of the mm-wave divided from a splitter are mixed together without wireless broadcast before one passing a phase shift. Among the $10 \mathrm{Gbit} / \mathrm{s} 4$ PAM signal conveyed over $40 \mathrm{~km}$ SMF, graphs of time-domain, frequency-domain and optical spectrum are measured out in different period. Moreover, the comparison of error vector magnitude curves between NonReturn-to-Zero (NRZ) [10] and 4 PAM under the different length of the fiber is accomplished.

\section{System Setup and Results}

Figure 2 Illustrates the configuration of the proposed scheme. At the transmitter, light-wave source emitted from two external cavity lasers (ECL1 and ECL2) as the continuous wave (CW) laser, the frequency tone spacing of the two ECLs is $60 \mathrm{GHz}$. The maximum line width of the two CWs is $10 \mathrm{MHz}$ and coupled together by a $3 \mathrm{~dB}$ optical coupler, where one (work frequency at $193.1 \mathrm{THz}$ ) is modulated intensity via a MZM driven with the $10 \mathrm{Gbit} / \mathrm{s}$ baseband 4 PAM signal and the other one (work frequency at $193.16 \mathrm{THz}$ ) without data modulation. The graph of time-domain and frequency-domain of the RF-4 PAM signal is presented in Figure 3(i) and Figure 3(ii), respectively. We can see that the main bandwidth of RF baseband is $5 \mathrm{GHz}$ because all the power is concentrated in the innerbroad band of $5 \mathrm{GHz}$.

Before transmitted over $40 \mathrm{~km}$ SMF with an erbium-doped fiber amplitude (EDFA), the time-domain diagram of the optical coupled signal shows in Figure 3(iii) and its optical spectrum shows in Figure 3(iv), the commonly used fiber parameters we setup are as shown in Table 1. $60 \mathrm{GHz}$ mm-wave is generated by two direct received optical sidebands beating together in a positive intrinsic-negative photodiode (PIN PD) with a bandwidth of $70 \mathrm{GHz}$ and a DC responsivity of $1 \mathrm{~A} / \mathrm{W}$ and dark current is $10 \mathrm{nA}$, the graphs of time-domain/frequency-domain are shown in Figure 3(v) and Figure 3(vi). After that, the process of wireless transmission removed that mm-wave is transformed into the baseband by the self-mixing immediately, using phase shifter can ensure that the initial phase of two channels signal consistent, relevant figures are as shown in Figure 3(vii) and Figure 3(viii). We assume the mm-wave $E_{m}(t)$ expressed simply as

$$
E_{m}(t)=A \cos \left(f_{m} t\right) \cdot\left[1+\cos \left(f_{r} t\right)\right]
$$

where $f_{m}$ and $f_{r}$ are the amplitude, high-frequency (60 GHz) and base-frequency (RF frequency) of the millimeter signal, then the electrical signal self-mixed $E_{r}(t)$ is 


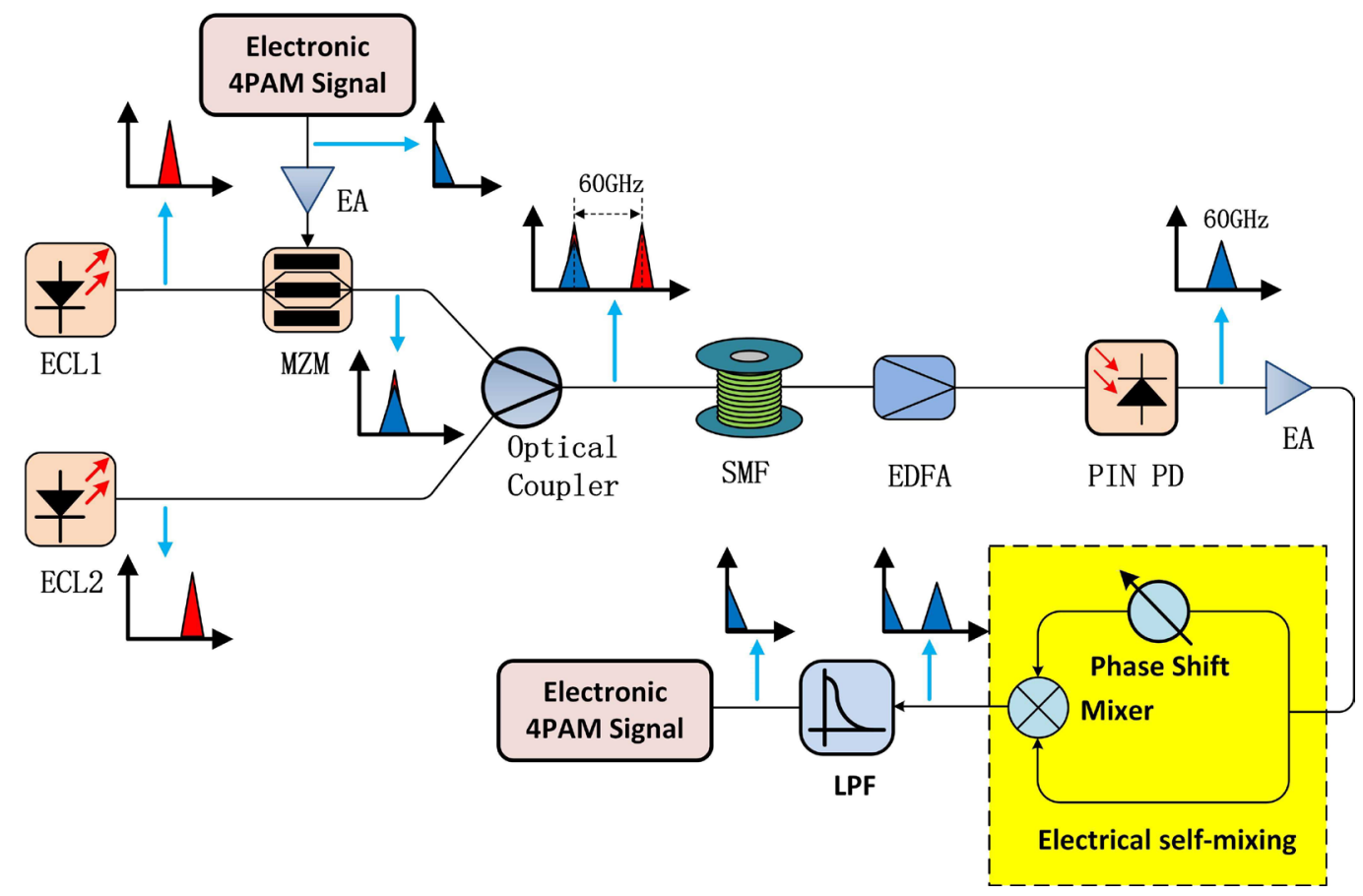

Figure 2. Schematic diagram of $60 \mathrm{GHz} 4 \mathrm{PAM}-\mathrm{RoF}$ optical transmission system set up (ECL: external cavity laser; EA: electrical amplifier; MZM: Mach-Zehnder modulator; EDFA: erbium doped fiber amplifier; PIN PD: positive intrinsic-negative photodiode; LPF: lower pass filter).
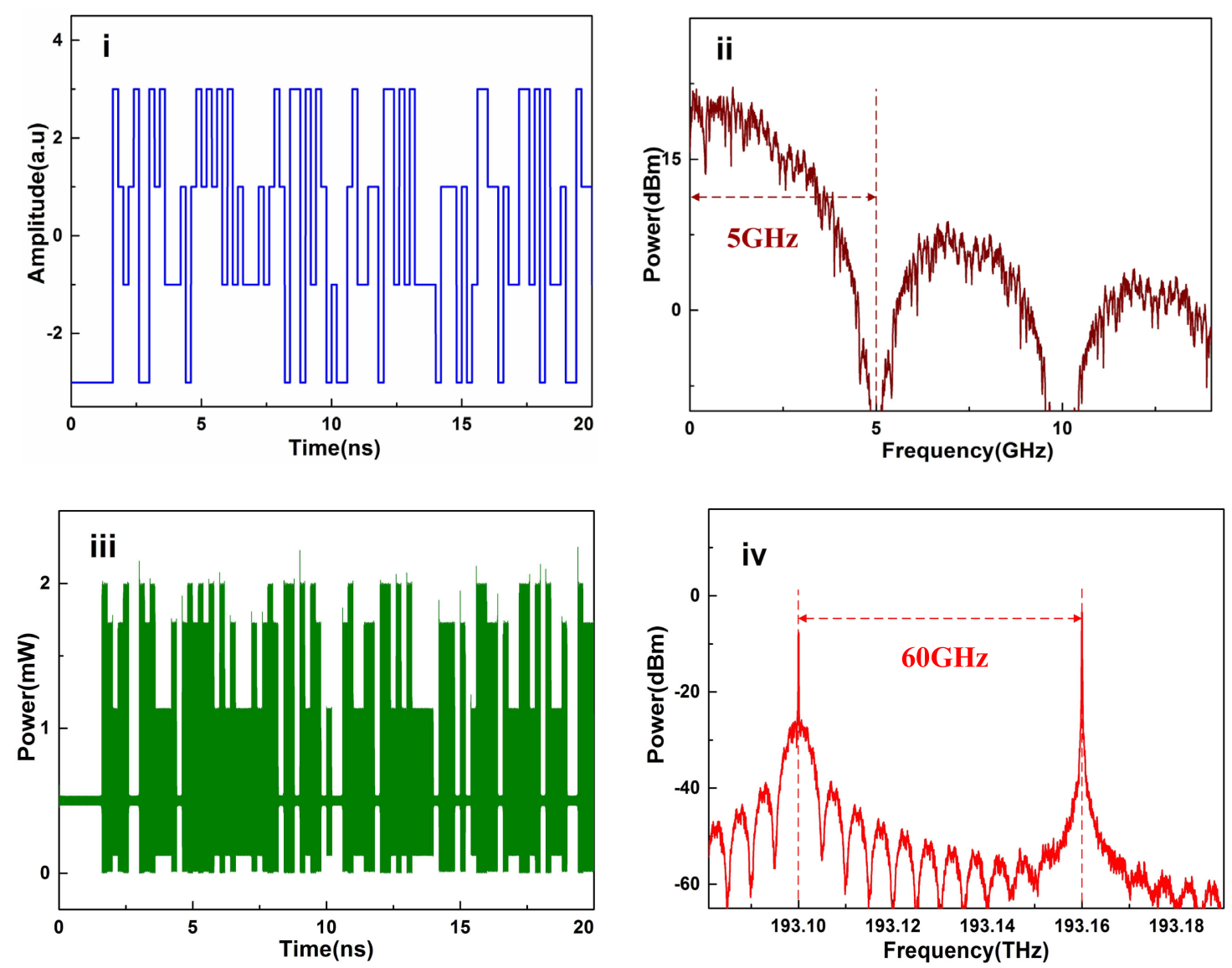

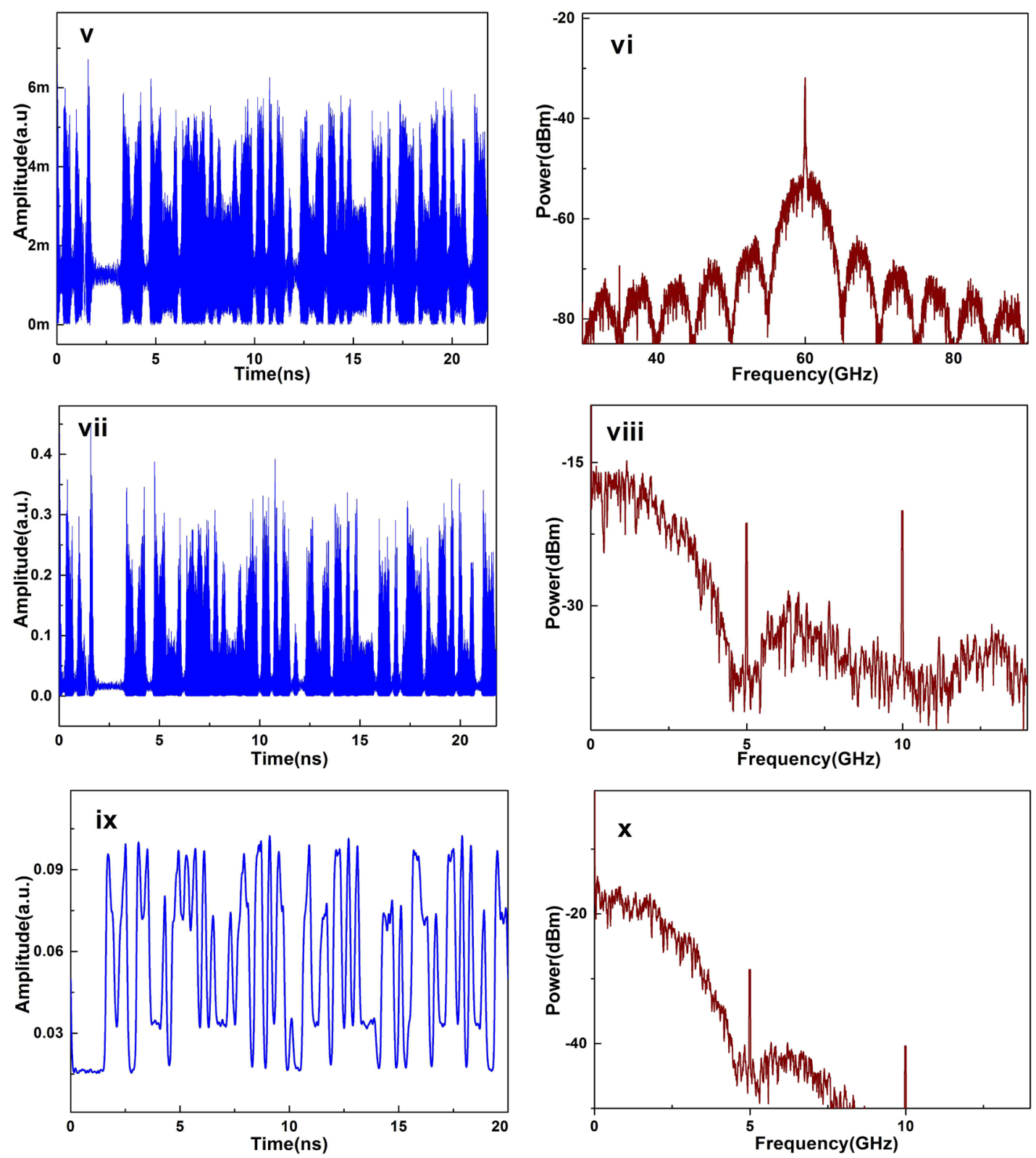

Figure 3. Time-domain wave, frequency-domain and optical spectrum in different stage of transmission.

$$
\begin{aligned}
E_{r}(t) & =E_{m}(t) \cdot E_{m}(t) \\
& =A^{2}\left[\cos \left(f_{r} t\right)+\frac{3}{4} \cos \left(2 f_{m} t\right)+\frac{1}{4} \cos \left(2 f_{r} t\right)\right. \\
& \left.+\cos \left(2 f_{m} t\right) \cos \left(f_{r} t\right)+\frac{1}{4} \cos \left(2 f_{m} t\right) \cos \left(2 f_{r} t\right)+\frac{3}{4}\right]
\end{aligned}
$$

Thus, the baseband $f_{r}$ can be filtered out with a low pass filter, we select the third-order Bessel filter as the LPF.

With the clock recovered, the time-domain and frequency-domain of the electrical 4 PAM signal demodulated are as shown in Figure 3(ix) and Figure 3(x).

From the EVM curves shown in Figure 4, NRZ performs better than 4 PAM selected in RoF system within length of $80 \mathrm{~km}$ fiber. However, the 4 PAM modulation has higher capacity than NRZ. 


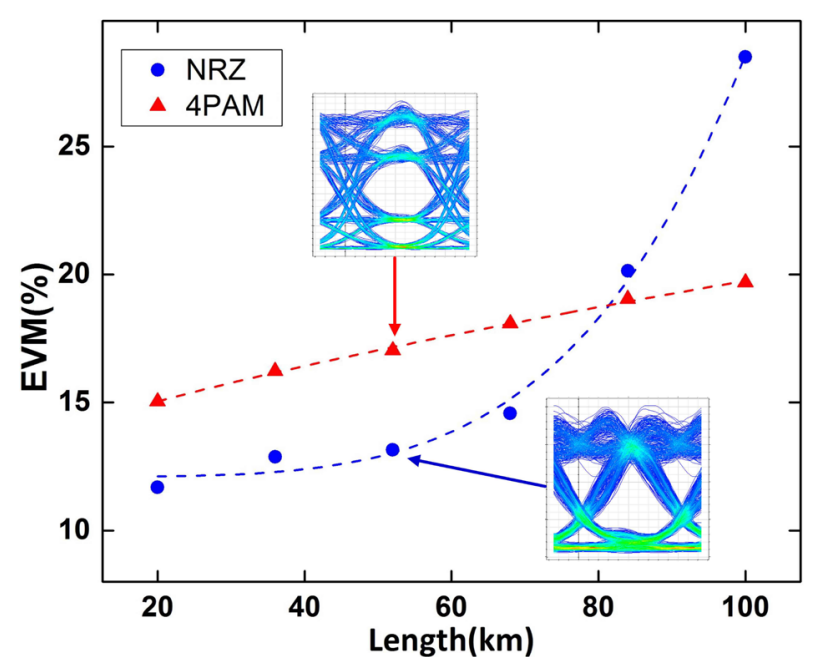

Figure 4. The EVM curves of NRZ and 4 PAM signal after transmission over different length fiber.

Table 1. The SMF parameters

\begin{tabular}{ccc}
\hline & Parameters & Value \\
& Length $(\mathrm{km})$ & 40 \\
SMF & Attenuation $(\mathrm{dB} / \mathrm{km})$ & 0.2 \\
parameters & Dispersion $(\mathrm{ps} / \mathrm{nm} / \mathrm{km})$ & 16.75 \\
& Dispersion slop $\left(\mathrm{ps} / \mathrm{nm}^{2} / \mathrm{km}\right)$ & 0.075 \\
& Nonlinear coefficient $\left(\mathrm{W}^{-1} \mathrm{~km}^{-1}\right)$ & 2.6 \\
\hline
\end{tabular}

\section{Conclusion}

We propose a $10 \mathrm{Gbit} / \mathrm{s} 4$ PAM transmitted in the RoF optical access system with a method of self-mixing to recover the RF signal. Different graphs of time-domain wave and frequency-domain are measured by the optical software of Optiwave, and the comparison of EVM between NRZ-RoF and 4 PAM-RoF under the various length of the fiber is accomplished, the result shows that NRZ performs better than 4 PAM selected in RoF system within $80 \mathrm{~km}$ fiber, but the capacity of 4 PAM modulation is higher than NRZ.

\section{Acknowledgements}

This work is partially supported by the National Natural Science Foundation of China (No. 61107064), the Chongqing University Innovation Team Founding (No. KJTD201320), the Chongqing Science and Technology Commission Foundation (No. cstc2014jcyjA 40046), the Science and Technology Special Funds in Wanzhou District, and the Chongqing Graduate Scientific Research Innovation Project (No. CYS15225).

\section{References}

[1] Tomkos, I., Kazovsky, L. and Kitayama, K.I. (2012) Next-Generation Optical Access Networks: Dynamic Bandwidth Allocation, Resource Use Optimization, and QoS Improvements [Guest Eeditorial]. IEEE Network, 26, 4-6. http://dx.doi.org/10.1109/MNET.2012.6172268

[2] Shao, Y.F., Gui, L., Wang, S.K., Luo, Y.X. and Tan, Z.F. (2014) 60 GHz Radio over Fiber System with 5 Gb/s 32 QAM-OFDM Downlink Signals Using Self-Mixing Homodyne Detection Technique. Applied Mechanics and Materials, 475-476, 828-831.

[3] Shao, Y.F., Wang, S.K., Wang, A.R., Shen, S.L., Chen, L. and Chen, F.P. (2014) 8PSK Signals with 50\% RZ Clock for Optical Access System Applications Using Phase Equalization Technique in MSPE. Applied Mechanics and Mate- 
rials, 716-717, 1099-1102. http://dx.doi.org/10.4028/www.scientific.net/AMM.716-717.1099

[4] Shao, Y., Wang, A., Luo, Y., Shen, S., Chen, L. and Chen, F. (2015) Novel Optical Access Scheme with 33\% RZ8PSK Downlink Signals Using Phase Equalization. 2015 5th International Conference on Instrumentation and Measurement, Computer, Communication and Control (IMCCC), 1268-1271. http://dx.doi.org/10.1109/IMCCC.2015.272

[5] Beas, J., Castanon, G., Aldaya, I., Aragón-Zavala, A. and Campuzano, G. (2013) Millimeter-Wave Frequency Radio over Fiber Systems: A Survey. IEEE Communications Surveys \& Tutorials, 15, 1593-1619. http://dx.doi.org/10.1109/SURV.2013.013013.00135

[6] Shao, Y., Chi, N., Fan, J. and Fang, W. (2012) Generation of 16-QAM-OFDM Signals Using Selected Mapping Method and Its Application in Optical Millimeter-Wave Access System. IEEE Photonics Technology Letters, 24, 1301303. http://dx.doi.org/10.1109/LPT.2012.2202387

[7] Shao, Y. and Chi, N. (2012) A Novel Scheme for Seamless Integration of RZ-DPSK-DWDM Optical Links with MIMO-OFDM System. Microwave and Optical Technology Letters, 54, 1676-1679. http://dx.doi.org/10.1002/mop.26891

[8] Shao, Y., Wang, Y. and Chi, N. (2013) 60-GHz RoF System with Low PAPR 16 QAM-OFDM Downlink Using PTS Segmentation. IEEE Photonics Technology Letters, 25, 855-858. http://dx.doi.org/10.1109/LPT.2013.2252425

[9] Ma, J. and Zhang, J. (2015) Full Duplex Fiber Link for Alternative Wired and Wireless Access Based on SSB Optical Millimeter-Wave with 4-PAM Signal. Optics Communications, 338, 578-584. http://dx.doi.org/10.1016/j.optcom.2014.11.039

[10] Shao, Y., Chi, N., Hou, C., Fang, W., Zhang, J., Huang, B., Li, X., Zou, S., Liu, X., Zheng, X. and Zhang, N. (2010) A Novel Return-to-Zero FSK Format for 40-Gb/s Transmission System Applications. Journal of Lightwave Technology, 28, 1770-1782. http://dx.doi.org/10.1109/JLT.2010.2048413

\section{Submit or recommend next manuscript to SCIRP and we will provide best service for you:}

Accepting pre-submission inquiries through Email, Facebook, LinkedIn, Twitter, etc. A wide selection of journals (inclusive of 9 subjects, more than 200 journals)

Providing 24-hour high-quality service

User-friendly online submission system

Fair and swift peer-review system

Efficient typesetting and proofreading procedure

Display of the result of downloads and visits, as well as the number of cited articles

Maximum dissemination of your research work

Submit your manuscript at: http://papersubmission.scirp.org/ 